\title{
A PRODUÇÃO CIENTÍFICA RESULTANTE DE TESES E DISSERTAÇÕES EM PROGRAMAS DE PÓS- GRADUAÇÃO EM EDUCAÇÃO FÍSICA NO PERÍODO DE 2013 A 2017
}

\author{
SCIENTIFIC PRODUCTION RESULTING FROM THESES AND DISSERTATIONS \\ IN GRADUATE PROGRAMS IN PHYSICAL EDUCATION IN 2013-2017
}

LA PRODUCCIÓN CIENTIIFICA RESULTANTE DE TESIS Y DISERTACIONES EN PROGRAMAS DE POSGRADO EN EDUCACIÓN FÍSICA EN EL PERÍODO DE 2013 A 2017

\author{
Jéssica Serafim Frasson*, Vicente Molina Neto*, \\ Elisandro Schultz Wittizorecki*
}

Palavras chave: Educação Física. Programas de Atividades científicas e tecnológicas. pós-graduação.

Resumo: Este estudo objetiva apresentar uma configuração da produção científica resultante de teses e dissertações da Educação Física (EF) brasileira nos programas de pós-graduação (PPG) da Área 21 entre os anos 2013/2017. Para tal, foi realizada uma busca no Catálogo de Teses e Dissertações da Capes, na Plataforma Sucupira e uma análise do Relatório de Avaliação Quadrienal da Área 21. Foram identificadas 2.969 produções, sendo 2.371 dissertações de mestrado e 598 teses de doutorado. Olhando para as produções, foi possível destacar a pluralidade e a polissemia do conhecimento na Área. Identificou-se, porém, também uma hegemonia que demonstra uma certa visão sobre uma forma específica de produzir/construir conhecimento, que é regido por aqueles que dominam o campo da EF com um maior capital científico, a subárea biodinâmica.

Keywords Physical Education. Postgraduate Programs. Scientific and technical activities.

Palabras clave: Educación Física. Programas de Posgrado. Actividades científicas y tecnológicas.
Abstract: This study describes scientific production resulting from thesis and dissertations about Brazilian Physical Education (PE) from Graduate Programs (PPGs) of Area 21, in 2013-2017. Search was conducted on CAPES Thesis \& Dissertation Catalog, Sucupira Platform, and the Quadrennial Evaluation Report of Area 21 was analyzed. A total of 2,969 works was found, of which 2,371 were dissertations and 598 were $\mathrm{PhD}$ theses. The analysis highlighted the plurality and polysemy of knowledge in the Area, but also hegemony that shows a certain view about a certain form of producing/building knowledge, which is governed by those who dominate the PE field with greater scientific capital, that is, the Biodynamic subarea.

Resumen: Este estudio tiene como objetivo presentar una configuración de la producción científica resultante de tesis y disertaciones de la Educación Física (EF) Brasileña en los Programas de Posgrado (PPGs) del Área 21, entre los años 2013 y 2017. Para ello, fue realizada una búsqueda en el Catálogo de Tesis y Disertaciones de la CAPES, en la Plataforma Sucupira y un análisis del Informe de Evaluación Cuadrienal del Área 21. Se identificaron 2.969 producciones, de las cuales 2.371 son disertaciones de maestría y 598 son tesis de doctorado. En el análisis de las producciones, fue posible destacar la pluralidad y la polisemia del conocimiento en el Área, pero también identificamos una hegemonía que demuestra una cierta visión sobre una determinada forma de producir/ construir conocimiento, que se rige por aquellos que dominan el campo de la EF con un mayor capital científico, la subárea Biodinámica.
*Universidade Federal do Rio Grande do Sul. Porto Alegre, RS, Brasil. E-mail: jehfrasson@ hotmail.com; vicente.neto@ufgrs.br; elisandro.witizorecki@ufrgs.br

Recebido em: 31-07-2018 Aprovado em: 04-06-2019 Publicado em: 16-12-2019

DOI: https://doi.org/10.22456/1982-8918.85355 (c) (1) \& L Licence (c) 


\section{INTRODUÇÃO}

Não chegam a ser novidade os diferentes embates teóricos que embalam a história da Educação Física como campo de conhecimento. Alguns estudos (FARINATTI, 1992; GAYA 1994; BRACHT, 1995; LOVISOLO; 1996; TAFFAREL; ESCOBAR, 1996) versam sobre o que ela é, pode ou deve ser, apresentando suas diferentes compreensões e perspectivas teóricoepistemológicas. Essas disputas e embates geraram aquilo que ficou conhecido como a crise da Educação Física (BRACHT, 1995). Essa mesma crise era uma necessidade, segundo Medina (1986) e Ghiraldelli Jr. (1988), que apontava para a ebulição da área em busca da sua identidade.

É possível destacar que as disputas na área ainda existem, mas intuímos que elas possam ter tomado outros contornos, ainda que busquem o mesmo objetivo: legitimidade. Ou seja, se antes a disputa era por uma identidade da área, hoje nos parece que ela está direcionada à ocupação do espaço social. No caso da pós-graduação, por exemplo, podemos pensar que a disputa é por capital científico, produção, acumulação de pontos, e, com isso, o argumento de que "se produzo mais, sou melhor" ou ainda a "condição" de apontar o que é mais ou menos científico. Nesse mesmo sentido, Stigger, Silveira e Myskiw (2015) chamam a atenção para a noção de cultura científica, e afirmam que esta é um campo de lutas em que se define o que é uma boa ciência e quais instituições e sujeitos estão autorizados a estabelecer as classificações dos produtos científicos.

Do mesmo modo, Carneiro, Ferreira Neto e Santos (2015) destacam que a ciência e a política são temáticas que geram polêmica no campo da Educação Física, pois: "[...] expõem fortemente as lógicas de produção do conhecimento dos sujeitos que a praticam, realçando tensões e tradições de cunho epistemológico que se alicerçam em pressupostos teóricos e orientações filosóficas distintas" (p. 7), e concluem que estas podem entrar em conflito ao serem debatidas pelos pares acadêmicos. Outros autores também já se demonstraram atentos a essas disputas na área e realizaram estudos que nos ajudaram a compreender a dinâmica estabelecida. Silva (1990), ao investigar as pesquisas de mestrado em Educação Física no Brasil, apresenta uma classificação dos estudos e as suas diferenças nas formas de fazer ciência. Manoel e Carvalho (2011), em um estudo sobre os programas de pós-graduação em Educação Física no Brasil, classificam-nos a partir das linhas de pesquisas três subáreas (biodinâmica, sociocultural e pedagógica) e ainda destacam, a partir das produções, uma atração (fatal) pela biodinâmica.

Lara (2016, p. 99), ao ensaiar sobre os pecados capitais da Educação Física, apresenta a gula como um dos elementos que acirra a disputa no campo, intensificando a ânsia pela produção. Segundo a autora, "[...] o cenário do 'produzir mais' passa a ser meta do pesquisador, o que o leva à gula por pontos, por reconhecimento nacional e internacional, por vezes amparada na superficialidade". Mais recentemente, Lazzarotti Filho et al. (2018) apresentaram as tendências do campo de conhecimento Educação Física brasileira a partir de análises documentais produzidas pela Área 21 da Capes, destacando que esses documentos causam impacto e estruturam a atividade científica no campo da Educação Física, demarcando os valores do capital científico do campo na disputa dos seus agentes e instituições.

Essas pesquisas nos levaram a refletir sobre o campo acadêmico-científico da Educação Física, sobre as disputas que permeiam, classificam e orientam a área. Nesse 
sentido, questionamo-nos sobre a produção científica que os PPG em Educação Física da Área 21 têm produzido e como eles têm se configurado no cenário científico brasileiro. Para dialogarmos com esse questionamento, propusemos aproximações e reflexões a partir da teoria do campo de Pierre Bourdieu e objetivamos, neste texto, apresentar uma configuração da produção científica resultante de teses e dissertações da Educação Física brasileira nos programas de pós-graduação da Área 21 entre os anos 2013/2017.

As informações foram acessadas a partir do Catálogo de Teses e Dissertações da Capes, do relatório de avaliação quadrienal da Área 21 e da Plataforma Sucupira. É importante destacar que elegemos os anos de 2013/2017 porque os dados foram inseridos no banco de dados da Capes somente a partir de 2013. Foram compilados 2.969 trabalhos, sendo 598 teses de doutorado e 2.317 dissertações de mestrado. Todas as fases de trabalho sobre essas produções se desenvolveram ao longo de aproximadamente nove meses.

O primeiro mês foi utilizado para a identificação e contabilização das produções no Catálogo de Teses e Dissertações da Capes, bem como para a realização do download dos materiais e do agrupamento dos arquivos em pastas dedicadas aos respectivos programas de pós-graduação, universidades e estados. A leitura dos títulos, resumos e palavras-chave das produções foi realizada num período de três meses, em concomitância à categorização das produções por subárea de conhecimento (biodinâmica, sociocultural e pedagógica).

Após a caracterização das produções nas respectivas subáreas, levamos aproximadamente dois meses para compilarmos todas as palavras-chave desses materiais, 0 que, junto à leitura dos títulos e resumos, auxiliou-nos a agrupar essas produções por temáticas de estudos dentro de cada subárea. Levamos cerca de um mês para realizarmos a busca e identificação das linhas de pesquisa e do número de professores de cada programa. Por fim, utilizamos os últimos dois meses para a construção, organização e reorganização da escrita deste texto.

\section{A PRODUÇÃO CIENTÍFICA DA EDUCAÇÃO FÍSICA BRASILEIRA NOS PROGRAMAS DE PÓS-GRADUAÇÃO}

Bourdieu (2004), em sua análise sobre a dinâmica dos campos, considera que os microcosmos sociais (os campos) são integrantes de um macrocosmo, o espaço social, lugar de diferenças e lutas entre diversos capitais. $O$ autor define o campo social como um espaço no qual os agentes se encontram em posições fixadas a priori, entendendo-o como "[...] 0 locus onde se trava uma luta concorrencial entre os atores em torno de interesses específicos que caracterizam a área em questão [...] e não é resultado das ações individuais dos agentes" (BOURDIEU, 1983, p. 19). Os campos são definidos a partir dos conflitos e das tensões no que diz respeito à sua própria delimitação e são construídos por redes de relações ou de oposições entre os agentes sociais (BOURDIEU, 1989; 2004). A teoria dos campos corresponde à pluralidade dos aspectos que constitui a realidade do mundo social.

Com essa noção de campo, identificamos a Educação Física como um campo acadêmico-científico (LAZZARROTTI FILHO, 2011) e apresentamos a sua produção no Brasil no que se refere às teses e dissertações produzidas na Área 21 entre os anos de 2013/2017. O campo acadêmico-científico da Educação Física é formado por programas de pós-graduação (PPG) que envolvem quatro áreas de atuação acadêmica e profissional: 
Educação Física, Fisioterapia, Fonoaudiologia e Terapia Ocupacional. O recente relatório de avaliação quadrienal da Área 21 identifica e apresenta nessas quatro áreas de avaliação 64 PPG, que oferecem cursos de mestrado $(95,3 \%)$ e doutorado $(57,8 \%)$ acadêmicos e cursos de mestrados profissionais (4,7\%). Segundo a avaliação quadrienal da área, finalizada em 2017, a Educação Física possui 34 PPG (53,10\%), a Fisioterapia e a Terapia Ocupacional contam com $20(31,25 \%)$ e a Fonoaudiologia possui um total de dez programas (15,65\%) (CAPES, 2017).

No caso da Educação Física, é possível destacar que a quantidade de cursos de pósgraduação diz também sobre a quantidade de produções do campo, ou seja, não é surpresa que a Educação Física, como a área de avaliação "maior", consequentemente, produz mais que a Fonoaudiologia, a Fisioterapia e a Terapia Ocupacional em termos quantitativos. No quadro 1, apontamos a distribuição das produções em cada um dos campos que compõem a Área 21:

Quadro 1 - Produção das teses e dissertações nas subáreas da Área 21 entre os anos de 2013 a 2017.

\begin{tabular}{|l|c|c|c|c|c|c|}
\hline Subáreas da Área de Avaliação & \multicolumn{2}{|c|}{ Dissertações } & \multicolumn{2}{c|}{ Teses } & \multicolumn{2}{c|}{ Total } \\
\hline Educação Física & 2.371 & $60,50 \%$ & 598 & $62,74 \%$ & 2.969 & $61 \%$ \\
\hline Fisioterapia e Terapia Ocupacional & 950 & $24,20 \%$ & 181 & $19 \%$ & 1.131 & $23,20 \%$ \\
\hline Fonoaudiologia & 593 & $15,30 \%$ & 174 & $18,26 \%$ & 767 & $15,70 \%$ \\
\hline Total & 3.914 & $100 \%$ & 953 & $100 \%$ & 4.876 & $100 \%$ \\
\hline
\end{tabular}

Fonte: Banco de teses da Capes, acesso 16 de outubro de 2017.

No Quadro 1, podemos identificar que a Educação Física foi responsável por $61 \%$ do conhecimento produzido, e que este representa 2.969 trabalhos, sendo 2.371 dissertações de mestrado e 598 teses de doutorado distribuídas ao longo dos 34 programas. A produção da Fisioterapia e da Terapia Ocupacional corresponde a 23,30\% e a da Fonoaudiologia, a 15,70\%. Com esse levantamento inicial, propomos apresentar e discutir a produção que diz respeito à Educação Física.

É possível destacar que a produção científica em Educação Física no Brasil sofreu sensível avanço com a criação dos cursos de mestrado e, posteriormente, de doutorado. $\mathrm{Na}$ esteira desse expressivo crescimento quantitativo e intelectual, os trabalhos científicos e os debates teóricos proliferaram e vêm contribuindo para a construção do conhecimento e para 0 constante processo de reflexão, ampliação e aprimoramento do campo de estudos que envolve a Educação Física. Mas, por outro lado, esse crescimento contribui também para uma busca desenfreada pelo produtivismo acadêmico. Esse fato é corroborado pelo aumento da produção de dissertações em Educação Física, principalmente a partir da década de 1980. De acordo com Silva et al. (1998), o número de dissertações defendidas até dezembro de 1984 (referente à produção de três cursos de mestrado) era de 76; em dezembro de 1994, este número cresceu seis vezes, perfazendo um total de 505 . Resgatando alguns números para a análise, temos, no momento desta pesquisa, 2.969 produções entre os anos de 2013 a 2017, sendo 598 teses de doutorado e 2.371 dissertações de mestrado.

Após esse levantamento geral da produção de teses e dissertações da Educação Física brasileira, o passo seguinte foi identificar as subáreas de conhecimento que expressam os enfoques teórico-metodológicos a partir dos quais esses trabalhos foram escritos e orientados. Para isso, classificamos as produções partindo da taxonomia proposta por Manoel e Carvalho 
(2011): biodinâmica, sociocultural e pedagógica. Também entendemos essas subáreas como agentes (BOURDIEU, 1983) que constroem, orientam e disputam o/no campo.

O jogo de forças político-epistemológicas existente na constituição da cultura e do campo científico da Educação Física foi indutor para a organização dos programas de pósgraduação, cujas linhas de pesquisa fazem parte de um mecanismo "hereditário" (SILVA, 1990). Para Bourdieu (2004, p. 52), o campo científico "[...] é um campo de forças dotado de uma estrutura e também um espaço de conflitos pela manutenção ou transformação desse campo". Ou seja, o universo da ciência é um universo de formas e produções simbólicas e, como tal, está submetido às mesmas leis que as teorias dos campos, assumindo suas formas específicas.

Partindo dessa compreensão, apresentamos, no Quadro 2, a configuração da produção acadêmico-científica do campo da Educação Física - no que se refere a teses e dissertações - nas respectivas subáreas e identificamos, ainda, como esses agentes estruturam o campo a partir das produções entre os anos de 2013/2017.

Quadro 2 - Produção de teses e dissertações em Educação Física defendidas entre os anos de 2013 a 2017.

\begin{tabular}{|l|c|c|c|c|c|c|}
\hline Subáreas & \multicolumn{2}{|c|}{ Dissertações } & \multicolumn{2}{c|}{ Teses } & \multicolumn{2}{c|}{ Total } \\
\hline Biodinâmica & 1.829 & $77,20 \%$ & 476 & $79,60 \%$ & 2.305 & $77,60 \%$ \\
\hline Sociocultural & 263 & $11,10 \%$ & 72 & $12,04 \%$ & 335 & $11,25 \%$ \\
\hline Pedagógica & 179 & $11,70 \%$ & 50 & $8,36 \%$ & 329 & $11,15 \%$ \\
\hline Total & 2.317 & $100 \%$ & 598 & $100 \%$ & 2.969 & $100 \%$ \\
\hline
\end{tabular}

Fonte: Elaborado pelos autores a partir dos dados do Banco de Teses da Capes, acesso 16 de outubro de 2017.

Com esse levantamento, identificamos que, tanto no número de teses quanto no de dissertações, há uma disparidade entre as subáreas, ou seja, há um agente que dispõe de mais produções que os outros. A subárea biodinâmica conta com 77,60\% (2.305) do total das produções, seguida pela sociocultural, com 11,25\% (335), e pela pedagógica, com $11,15 \%$ (329). Ao analisarmos por produtos, também é possível identificar que $77,20 \%$ (1.829) das dissertações e 79,60\% (476) das teses são produzidas e orientadas na subárea biodinâmica.

Bourdieu (2004, p. 20) destaca que, no campo científico, "[...] estão inseridos os agentes e as instituições que produzem, reproduzem ou difundem [...] a ciência". Essa produção, reprodução ou difusão pode ser representada por meio do capital científico, que "consiste no reconhecimento (ou no crédito) atribuído pelo conjunto de pares-concorrentes no interior do campo científico" (2004, p. 26). Ou seja, o capital científico é uma forma de capital simbólico que se baseia em relações de conhecimento e reconhecimento dentro do campo; segundo Lebaron (2017, p. 102), ele "[...] é definido pelo 'olhar' depositado (o 'valor' dado)" pelo grupo social sobre um determinado sujeito ou grupo.

De acordo com Bourdieu (1983, p. 122), o que está em jogo no campo científico é o monopólio da "autoridade científica [...] ou [...] o monopólio da competência científica", que pode ser compreendida enquanto capacidade de falar e de agir legitimamente. Ou seja, aquilo que é socialmente outorgado a um determinado agente ou grupo passa a legitimar e definir as estruturas do campo, caracterizando, assim, aqueles que dominam e os que são dominados. Desse modo, as produções científicas dos grupos acabam legitimando e estruturando o campo acadêmico-científico da Educação Física e, portanto, caracterizam o capital simbólico dos 
grupos sociais que difundem a ciência dentro do campo. Neste trabalho, chamamos a atenção para parte dessa produção: as teses de doutorado e dissertações de mestrado.

Nesse sentido, voltando ao Quadro 2 podemos perceber que a subárea biodinâmica apresenta um quantitativo de produções maior que as demais subáreas, portanto ela se torna o agente com mais capital científico e simbólico dentro do campo. As subáreas sociocultural e pedagógica se assemelham e mantêm proporcionalidades parecidas, uma vez que têm perspectivas teórico-metodológicas relativamente semelhantes, isto é, pautam-se em diferentes pressupostos ontológicos e tempos de pesquisa, distintos da biodinâmica. Em outros estudos (FRASSON et al. 2015; 2017; MOLINA NETO et al. 2016), apresentamos que o aumento significativo de produções da biodinâmica é resultado dos ciclos que estão estabelecidos dentro de cada programa. Ou seja, a quantidade de orientandos, orientadores, linhas de pesquisa e até mesmo o número de bolsas de estudo acabam retroalimentando o ciclo de (re)produção estabelecido nos programas do campo acadêmico-científico.

A partir de Bourdieu e Passeron (2014), podemos pensar que essa retroalimentação se dá devido à posição que um agente ocupa na estrutura do campo. Assim, as relações entre os agentes (dominantes e dominados) podem ou não gerar modificações nas relações de poder, pois aquilo que forma a estrutura de um campo é a distribuição do capital científico e simbólico entre os membros, o que, por sua vez, acaba lhes conferindo pesos e medidas distintas, mais e menos poderes políticos dentro do microcosmo em questão.

Nesse mesmo sentido, concordamos com Bourdieu (2004, p.34) quando destaca que, no mundo da ciência, existem "[...] relações de força, de concentração e disputas de poder, capital e até mesmo de monopólios, relações sociais que implicam na apropriação dos meios de dominação produção e (re)produção". Ou seja, a tendência hegemônica de uma forma de fazer ciência no campo acadêmico-científico da Educação Física brasileira perdura já há alguns anos.

A partir do Quadro 2, identificamos que dos 34 programas de pós-graduação em Educação Física, 11 não oferecem curso de doutorado. Com isso, destacamos que a não oferta do curso de doutorado pode influenciar na estrutura do campo, principalmente para as subáreas sociocultural e pedagógica, que apresentam um número de produções menor que a biodinâmica, uma vez que a oferta do curso de doutorado também pode possibilitar novos debates, espaços e oportunidades de produzir conhecimento nas diferentes subáreas do campo acadêmico-científico da Educação Física. A base empírica para essa assertiva é reforçada também pelos programas que, além de não ofertarem o curso de doutorado, às vezes não dispõem de linhas de pesquisa que contemplem as subáreas sociocultural e pedagógica, conforme quadro a seguir:

Quadro 3 - Linhas de pesquisa dos Programas por subárea.

\begin{tabular}{|l|c|c|}
\hline Linhas de Pesquisa & $\mathrm{N}^{\circ}$ & $\%$ \\
\hline Subárea Biodinâmica & 105 & $70 \%$ \\
\hline Subárea Sociocultural & 30 & $20 \%$ \\
\hline Subárea Pedagógica & 15 & $10 \%$ \\
\hline Total & 150 & $100 \%$ \\
\hline
\end{tabular}

Fonte: Programas na Plataforma Sucupira, acesso 16 de outubro de 2017 
A biodinâmica opera $70 \%$ das linhas de pesquisa oferecidas pelos 34 programas da Área 21, seguida pela sociocultural, com $20 \%$, e pela pedagógica, com $10 \%$. Esses $10 \%$ destinados à subárea pedagógica representam 15 linhas de pesquisa, de um total de 150. Esse dado também nos leva a pensar que dos 34 programas, 20 não se dedicam a construir conhecimento nessa área, ocasionando uma lacuna na produção de conhecimento de determinadas subáreas.

Assim, podemos pensar que essas lacunas existentes acabam outorgando uma forma de fazer ciência no campo da Educação Física, uma vez que o número de programas que não ofertam doutorado, junto com o de programas que não oferecem linhas de pesquisa na subárea sociocultural e pedagógica, reproduz e difunde o modelo científico hegemônico estabelecido na área.

Para Bourdieu, "[...] a definição dominante das coisas boas de se dizer e dos temas dignos de interesse é um dos mecanismos ideológicos que fazem com que coisas também muito boas de se dizer não sejam ditas e com que temas não menos dignos de interesse não interessem a ninguém" (2015, p. 37). 0 autor também destaca que, nas disputas políticas de poder simbólico, "[...] os pesquisadores ou as pesquisas dominantes definem o que é, num dado momento do tempo, o conjunto de objetos importantes" (BOURDIEU, 2004, p. 25), estabelecendo, assim, aquilo que é digno de prestígio ou não, aquilo que é científico ou não.

Dessa forma, a reprodução das relações de força estabelecidas no campo acadêmicocientífico da Educação Física pode cristalizar e estruturar as relações dos grupos sociais. Apresentamos outro dado empírico que nos ajuda a sustentar essa discussão. No quadro a seguir, identificamos o número de professores orientadores e as subáreas de conhecimento em que estão credenciados, construindo/produzindo conhecimento nos programas de pósgraduação.

Quadro 4 - Professores credenciados nos PPG da Área 21 no ano de 2017.

\begin{tabular}{|l|c|c|}
\hline Professores credenciados por linhas de pesquisa & $\mathbf{N}^{\circ}$ & $\%$ \\
\hline Subárea Biodinâmica & 536 & $78,40 \%$ \\
\hline Subárea Sociocultural & 95 & $14 \%$ \\
\hline Subárea Pedagógica & 52 & $7,60 \%$ \\
\hline Total & 683 & $100 \%$ \\
\hline
\end{tabular}

Fonte: Dados cadastrais dos docentes dos PPG na Plataforma Sucupira, acesso 29 de outubro de 2017.

Segundo a Plataforma Sucupira, nos 34 programas de pós-graduação em Educação Física na Área 21, temos 683 professores credenciados, os quais constroem e produzem conhecimento em uma ou mais subárea da Educação Física. A subárea biodinâmica conta com 78,40\% (536) desses professores, a sociocultural, com 14\% (95), e a subárea pedagógica, com 7,60\% (52). Em síntese, e de forma geral, é possível destacar que os 683 professores credenciados em uma ou mais das 105 linhas de pesquisas relacionadas à subárea biodinâmica produziram, junto a orientandos, entre os anos de 2013/2017, 476 teses de doutorado e 1.829 dissertações de mestrado. Na subárea sociocultural, os 95 professores, credenciados nas 30 linhas, foram responsáveis pela orientação de 72 teses de doutorado e 263 dissertações de mestrado. Enquanto isso, a atividade dos 52 professores da subárea pedagógica, que 
constroem e produzem conhecimento em uma ou mais das 15 linhas de pesquisa, resultou em 50 teses de doutorado e 279 dissertações de mestrado entre os anos de 2013/2017.

Dessa forma, os dados apresentados nesse panorama geral sobre a configuração do cenário científico brasileiro nos programas de pós-graduação em Educação Física indicam uma certa disparidade das produções, contexto no qual há uma tendência de concentração em uma das subáreas em detrimento das outras. Também destacamos que o capital científico produzido acentuadamente pela subárea biodinâmica diz respeito ao lugar ocupado por ela na estrutura do campo. Ou seja, nos momentos de avaliação dos programas, os professores e estudantes vinculados a essa subárea detêm, segundo Bourdieu (2004), um determinado "prestígio" e maior reconhecimento pelos pares no campo.

Assim, "[...] a estrutura do campo científico é determinada pelo estado das relações de força entre as cientistas, o que resulta, por sua vez, das lutas anteriores e vai orientar as estratégias de cada um" (RAGOUET, 2017, p. 68). Assim, podemos pensar que as lutas, embates e disputas no campo se configuram como hereditárias, e alertamos para a não modificação do campo acadêmico-científico desde os primeiros estudos (SILVA, 1990; SILVA et al. 1998; FARINATTI, 1992; AVILA, 2008; LAZZAROTTI FILHO, 2011) sobre a temática. Outro elemento que nos ajuda a sustentar essa reflexão sobre a configuração hereditária do campo acadêmico-científico da Educação Física pode ser analisado nas próprias abordagens teórico-metodológicas das teses e dissertações.

Ao analisarmos nosso material empírico, identificamos uma predominância das pesquisas quantitativas e descritivas vinculadas aos estudos realizados na subárea biodinâmica. Dos $77,60 \%$ produtos dessa subárea, $70 \%$ se apropriaram dessa forma de fazer pesquisa, enquanto $6 \%$ utilizaram a pesquisa de abordagem quali-quanti e 1,60\% mobilizaram a pesquisa qualitativa como abordagem escolhida para realização do estudo. 0 contrário é visto nas teses e dissertações vinculadas às subáreas sociocultural $(11,25 \%)$ e pedagógica (11,15\%). Dos $22,40 \%$ total das produções nessas subáreas, $20 \%$ se apropriam da abordagem qualitativa para a escolha e realização dos estudos, enquanto 1,4\% utilizaram da abordagem quali-quanti e $1 \%$ optou pela abordagem quantitativa.

Esses dados nos apresentam que a escolha por uma forma de fazer pesquisa não é apenas mera coincidência, ou seja, as pesquisas realizadas na subárea da biodinâmica tendem a ser orientadas por pressupostos teórico-metodológicos ligados a Ciências Naturais (AMADIO; BARBANTI, 2000) e, por sua vez, apropriam-se, predominantemente, de instrumentos de investigação de caráter quantitativo. Por outro lado, as pesquisas realizadas nas subáreas sociocultural e pedagógica tendem a ser orientadas por pressupostos teórico-metodológicos ligados a Ciências Sociais (MINAYO, 1996) e se apropriam de instrumentos de pesquisa, majoritariamente, de caráter qualitativo.

Assim, buscamos identificar as opções teórico-metodológicas utilizadas pelos autores nas teses e dissertações. Compreendemos, ainda, que as subáreas sociocultural e pedagógica compartilham de premissas metodológicas muito similares e se diferem largamente da subárea biodinâmica, conforme esquematizamos na Figura 1 a seguir: 
Figura 1 - Opções teórico-metodológicas utilizadas nas teses e dissertações em Educação Física defendidas entre os anos de 2013 a 2017.

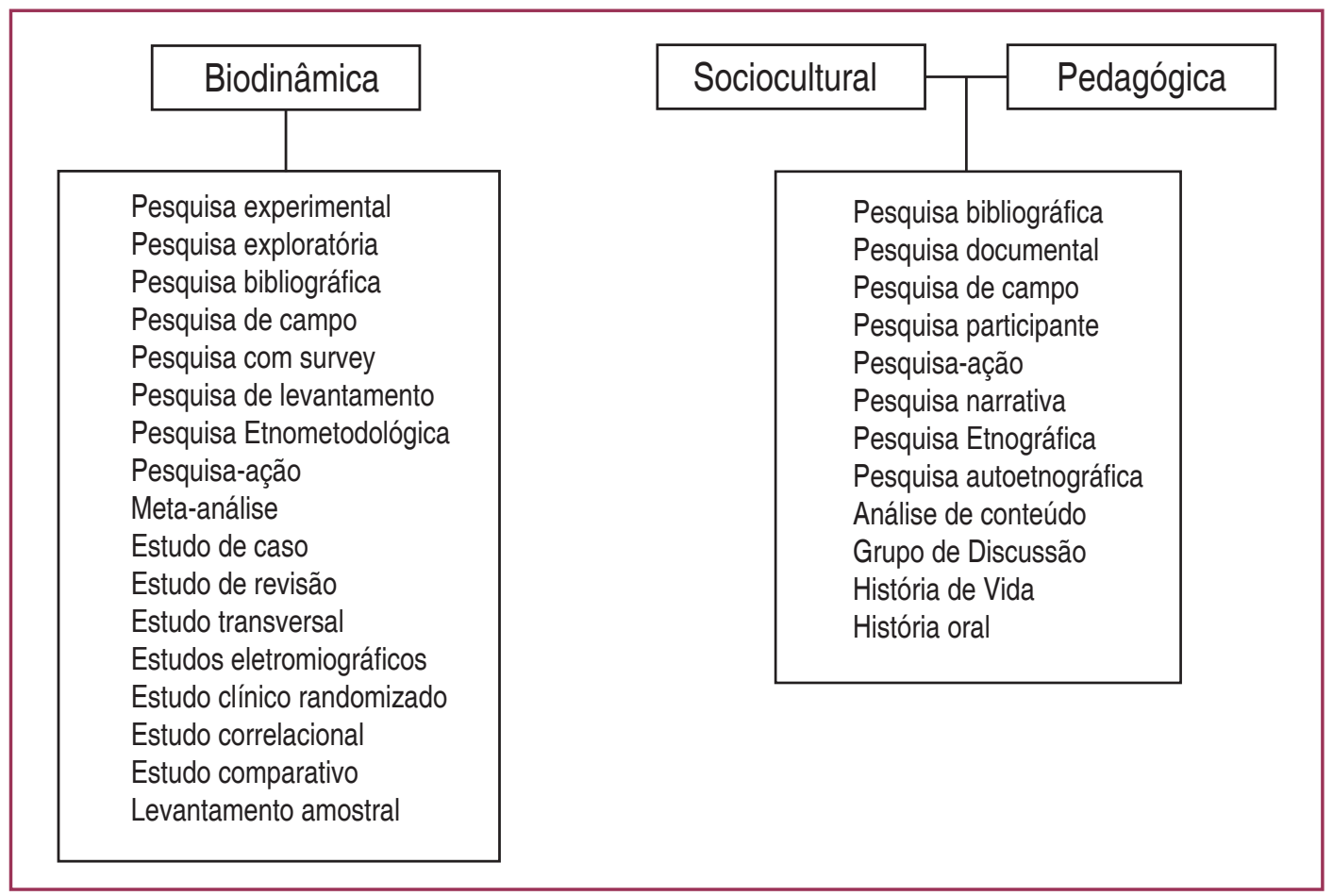

Fonte: Autores, a partir das teses e dissertações em Educação Física defendidas entre os anos de 2013 a 2017.

Identificamos que as produções vinculadas às subáreas sociocultural e pedagógica se apropriaram de metodologias de pesquisa que, de forma geral, não se preocupam com representatividade numérica, centrando-se no aprofundamento, na compreensão e na explicação da dinâmica dos grupos e relações sociais. Vinculando essa forma de fazer pesquisa às Ciências Sociais, apropriamo-nos do entendimento de Minayo (1996, p. 20) ao destacar que as Ciências Sociais são ideológicas, em sua essência, portanto a "visão de mundo do pesquisador e dos atores sociais estão implicadas em todo o processo de conhecimento, desde a concepção do objeto até o resultado do trabalho". Foi possível entender com essas teses e dissertações que, a partir das metodologias escolhidas, os autores endereçam seus trabalhos a um universo de significados, motivos, aspirações, crenças, valores e atitudes, enfatizando um espaço profundo das relações, dos processos e dos fenômenos que não podem ser reduzidos à operacionalização de variáveis.

Com uma outra perspectiva de fazer ciência na Educação Física, foi possível identificar no conjunto de pesquisas vinculadas à biodinâmica a potência do método mais voltado ao Positivismo (TRIVIÑOS, 1987), ligado às Ciências Naturais, que, segundo Demo (1995, p. 23), têm uma perspectiva de pesquisa "mensurável, testável, operacionalizável". Assim, entendemos a partir desses estudos que as opções teórico-metodológicas escolhidas focaram, em sua maioria, em resultados que podem e são quantificáveis, mensuráveis e, na maioria das vezes, generalizáveis, nos quais tudo ou quase tudo é apresentado (e representado) por uma linguagem matemática, na qual a estatística é a ferramenta mais requerida e indica a apropriação desses estudos por um viés empírico-analítico de fazer ciência.

Não chega a ser novidade que as pesquisas vinculadas às Ciências Naturais tendam a dominar as pesquisas científicas em muitas áreas de conhecimento (KUHN, 2017; 
FEYERABEND, 1977; BACON, 2007), e o mesmo acontece com o campo acadêmico-científico da Educação Física (BRACHT, 1995; 2015; RUBIO E CARVALHO, 2001; STIGGER, 2015). Os dados apresentados e discutidos ao longo deste texto nos mostram como a subárea biodinâmica concentra o maior capital científico (BOURDIEU, 1983, 2004) no que diz respeito às teses e dissertações da área. Segundo Stigger (2015, p. 8), a não "heterogeneidade acaba por materializar-se em um processo de desigualdade entre pesquisadores das diferentes áreas de investigação". No mesmo sentido, Bracht (2015) afirma que essa cristalização pode acabar asfixiando ou abafando formas alternativas de produzir conhecimento e pensar.

Ao analisar as disputas no campo científico, Bourdieu (1983, p. 136) afirma que ele é sempre o "[...] lugar de luta, entre agentes desigualmente dotados de capital específico e, portanto, desigualmente capazes de se apropriarem do produto do trabalho científico". Assim, entendemos que os debates e enfrentamentos epistemológicos que atravessam o mundo da ciência encobrem estratégias de manutenção, de exclusão ou de conquista do poder de impor uma determinada definição do que é o "científico" na medida em que se nega ou se despende pouca atenção às outras formas de conhecimento por elas não se pautarem pelos princípios epistemológicos e pelas regras metodológicas daqueles que estão detidos de autoridade ou competência científica, os agentes dominantes.

O autor ainda afirma que a ciência, e/ou "[...] a legitimidade da ciência e a utilização legítima da ciência são motivos permanentes de luta no mundo social e no próprio seio do mundo da ciência" (BOURDIEU, 2008, p. 17). Nesse sentido, concordamos com 0 autor e destacamos que o processo científico ou a construção da ciência no campo acadêmico científico da Educação Física precisa ser constantemente interrogado para que sustentemos a pluralidade e polissemia do conhecimento que ela pode contemplar, para que, cada vez mais, as diferentes formas de fazer e construir ciência sejam respeitadas, valorizadas e representadas no/pelo campo.

\section{CONSIDERAÇÕES FINAIS}

Fechamos nossas reflexões destacando que os trabalhos analisados neste estudo partem de princípios teórico-metodológicos que condicionam e conduzem o olhar do pesquisador para o fenômeno a partir de uma determinada perspectiva e princípios, aqueles escolhidos pelos autores e que melhor se adequam às suas pesquisas. Retomando a questão norteadora deste estudo - que conhecimento os PPG da Área 21 têm produzido, e como eles têm se configurado no cenário científico brasileiro? -, compreendemos que os 2.969 produtos, de uma forma ou de outra, demonstram que as pesquisas da subárea biodinâmica desvelam e explicam aspectos do movimento humano que as subáreas sociocultural e pedagógica não se preocupam em explicar. Do mesmo modo, a pesquisa nas subáreas sociocultural e pedagógica desvelam e possibilitam compreensões da cultura do movimento que a biodinâmica não objetiva fazer. Isso possibilita a compreensão da complexidade, da beleza, das singularidades do movimento humano e sua transposição para o mundo da vida, demonstra o conjunto, 0 todo. Em outras palavras, são as sínteses do conhecimento que se produz em todas as suas subáreas que direcionam o desenvolvimento científico da Educação Física ao encontro da relevância humana e social. 
Analisando a configuração do cenário científico nos programas de pós-graduação em Educação Física na Área 21, destacamos que as pesquisas realizadas na pós-graduação apresentam inter-relações necessárias com outros campos do conhecimento (SÁNCHEZ GAMBOA, 1994), e que essas inter-relações constituem a pluralidade e a polissemia do conhecimento na área. Identificamos, ainda, uma hegemonia que demonstra uma certa visão sobre uma forma de fazer/produzir/construir conhecimento na área, reconhecida como a subárea biodinâmica. Esse agente detém o maior capital científico e, por vezes, monopoliza a produção científica no campo acadêmico-científico da Educação Física.

Por fim, destacamos que as Ciências Sociais, ou as abordagens teórico-metodológicas, como alguns autores preferem se referir aos paradigmas (DEMO, 1995; SÁNCHEZ GAMBOA, 1994), distinguem-se das utilizadas nas Ciências Naturais. Por exemplo, diferenciam-se pelas formas de abordar os problemas, selecionar algumas técnicas, seguir diversos roteiros ou métodos, utilizar autores e teorias e fundar o conhecimento em pressupostos epistemológicos diferentes. Isso não significa que devemos ter uma visão binária sobre a construção do conhecimento ou sobre as formas de construir ciência, mas que a recuperação da unidade e articulação lógica desses elementos resulta em diferentes estilos ou maneiras de pesquisar e produzir conhecimentos. Na medida em que estes se expandem dentro da comunidade científica, constituem paradigmas ou modelos de fazer ciência, caminhando para a pluralidade epistemológica dentro do campo científico da área. Assim, destacamos que é necessário pensar na pluralidade, na multiplicidade, na disseminação da área e nas diferentes possibilidades que ela proporciona para que as três subáreas possam construir/produzir ciência no campo da Educação Física.

\section{REFERÊNCIAS}

AMADIO, Alberto Carlos; BARBANTI, Valdir José (Orgs.). Biodinâmica do movimento humano e suas relações interdisciplinares. São Paulo: Estação Liberdade, 2000.

AVILA, Astrid Baecker. A pós-graduação em Educação Física e as tendências na produção de conhecimento: 0 debate entre realismo e anti-realismo. 2008. Tese (doutorado) - Universidade Federal de Santa Catarina, Centro de Ciências da Educação, Programa de Pós-Graduação em Educação, Florianópolis, 2008.

BACON, Francis. 0 progresso do conhecimento. São Paulo: Editora: UNESP, 2007.

BOURDIEU, Pierre. O campo científico. In: ORTIZ, Renato (Org.). Pierre Bourdieu: Sociologia. São Paulo: Ática, 1983. p.122-155.

BOURDIEU, Pierre. O poder simbólico. Rio de Janeiro: Bertrand Brasil, 1989.

BOURDIEU, Pierre. Os usos sociais da ciência: por uma sociologia clínica do campo científico. São Paulo: Editora UNESP, 2004.

BOURDIEU, Pierre. Para uma Sociologia da Ciência. Lisboa: Edições 70, 2008. 
BOURDIEU, Pierre. Método científico e hierarquia social dos objetos. In: NOGUEIRA, Maria Alice; CATANI, Afrânio (Org.). Pierre Bourdieu Escritos de Educação. 16. ed. Petrópolis: Vozes, 2015. p. 39-64.

BOURDIEU, Pierre; PASSERON, Jean-Claude. A Reprodução: elementos para uma teoria do sistema de ensino. 7. ed. Petrópolis: Vozes, 2014.

BRACHT, Valter. Mas, afinal, o que estamos perguntando com a pergunta "o que é Educação Física". Movimento, v. 2, n. 2, p. 1-8, 1995.

BRACHT, Valter. Educação Física, método científico e reificação. In: STIGGER, Marco Paulo (Org.). Educação Física + Humanas. Campinas: Autores Associados, 2015. p. 8-21.

CAPES. Coordenação de Aperfeiçoamento de Pessoal de Nível Superior. Comissão De Área Da Educação Física, Fisioterapia, Fonoaudiologia e Terapia Ocupacional. Documento de área - 2017. Disponível em: http://www.capes.gov.br/images/stories/download/avaliacao/relatorios-finaisquadrienal-2017/20122017-EDUCACAO-FISICA-quadrienal.pdf.Acesso em: 10 set. 2018.

CARNEIRO, Felipe Ferreira Barros; FERREIRA NETO, Amarílio; SANTOS, Wagner dos. (Org.). Práticas científicas em Educação Física: tradições e tensões. Curitiba: CRV, 2015.

CARVALHO, Yara Maria; RUBIO, Katia. (Org.). Educação Física e Ciências Humanas. São Paulo: Hucitec, 2001.

DEMO, Pedro. Metodologia Científica em Ciências Sociais. 3. ed. rev. ampl. São Paulo: Atlas: 1995.

FARINATTI, Paulo de Tarso Veras. Pesquisa em Educação Física no Brasil: por um compromisso com a evolução. In: FARIAS JÚNIOR, Alfredo Gomes, FARINATTI, Paulo de Tarso Veras. Pesquisa e produção do conhecimento em Educação Física. Rio de Janeiro: Ao livro Técnico, 1992. p.73-76.

FEYERABEND, Paul. Contra o método. Rio de Janeiro: Livraria Francisco Alves, 1977.

FRASSON, Jéssica Serafim et al. A representatividade dos temas relacionados a educação básica nas produções da Área 21 nos PPGS da região sul do Brasil. In: CONGRESSO BRASILEIRO DE CIÊNCIAS DO ESPORTE, 20., CONGRESSO INTERNACIONAL DE CIÊNCIAS DO ESPORTE, 7. Anais... Goiânia, 2017. p.1003-1008.

FRASSON, Jéssica Serafim et al. O conhecimento produzido no programa de pós-graduação em ciências do movimento humano da universidade federal do rio grande do sul. In: CONGRESSO BRASILEIRO DE CIÊNCIAS DO ESPORTE E 21., CONGRESSO INTERNACIONAL DE CIÊNCIAS DO ESPORTE, 6. Anais... Vitória, 2015. p.1-16.

GAYA, Adroaldo César. Mas afinal o que é Educação Física? Movimento, v. 1, n. 1, p. I-IV, 1994.

GHIRALDELLI JÚNIOR, Paulo. Educação física progressista: a pedagogia crítico-social dos conteúdos e a educação física brasileira. São Paulo: Loyola, 1988.

KUHN, Thomas. A estrutura das revoluções científicas. 13. ed. São Paulo: Perspectiva, 2017.

LARA, Larissa Michelle. Os pecados capitais da Educação Física brasileira e suas demarcações constitutivas. Educação e Fronteiras, v. 6, n. 18, p. 94-110, set./dez. 2016.

LAZZAROTTI FILHO, Ari. 0 modus operandi do campo acadêmico-científico da Educação Física no Brasil. 2011. 147f. Tese (Doutorado em Educação Física) - Universidade Federal de Santa 
LAZZAROTTI FILHO, Ari et al. Tendências no campo da educação física brasileira. Análise dos documentos produzidos pela área 21 da Capes. Revista Brasileira de Ciências do Esporte, v. 40, n. 3, p. 213-241, jul./set. 2018.

LEBARON, Frédéric. Capital. In: CATANI, Afrânio; NOGUEIRA et al. (Org.). Vocabulário Bourdieu. Belo Horizonte: Autêntica, 2017. p.101-103.

LOVISOLO, Hugo. Hegemonia e legitimidade nas ciências dos esportes. Motus Corporis, v. 3, n. 2, p. $51-72,1996$.

MANOEL, Edson de Jesus; CARVALHO, Yara. M. Pós-graduação na educação física brasileira: a atração (fatal) para a biodinâmica. Revista de Educação e Pesquisa, v. 37, n. 2, p. 389-406, 2011.

MEDINA, João Paulo Subirá. A Educação Física cuida do Corpo e "Mente". Campinas: Papirus, 1986.

MINAYO, Maria Cecília de Souza. O Desafio do Conhecimento: pesquisa qualitativa em saúde. 4. ed. São Paulo: HUCITEC/ABRASCO, 1996.

MOLINA NETO, Vicente et al. Teses especulativas sobre a produção de conhecimento, a formação e a construção docente em educação física. In: SILVA, Paula Cristina da Costa et al. (Org.). Territorialidade e diversidade regional no Brasil e América Latina: suas conexões com a Educação Física e as Ciências do Esporte. Florianópolis: Tribo da llha, 2016. v.2, p. 91-117.

RAGOUET, Pascal. Campo científico. In: CATANI, Afrânio; NOGUEIRA et al. (Org). Vocabulário Bourdieu. Belo Horizonte, Autêntica, 2017. p. 68-71.

SÁNCHEZ GAMBOA, Silvio Ancisar. Pesquisa em Educação Física: as inter-relações necessárias. Motrivivência, n. 5/7, p. 34-46, dez. 1994.

SILVA, Rossana Valéria Souza e. Mestrados em educação física no Brasil: pesquisando suas pesquisas. Santa Maria, 1990. 251f. Dissertação (Mestrado em Ciências do Movimento Humano) Universidade Federal de Santa Maria, Santa Maria, RS, 1990.

SILVA, Rossana Valéria Souza et al. (Org.). Produção científica em educação física e esportes: dissertações e teses. Uberlândia: UFU/NUTESES, 1998.

STIGGER, Marco Paulo. Educação Física + Humanas. Campinas: Autores Associados, 2015.

STIGGER, Marco Paulo; SILVEIRA, Raquel da; MYSKIW, Mauro. O processo de avaliação da PósGraduação em Educação física e Ciências do Esporte no Brasil e algumas das suas repercussões cotidianas. In: RECHIA, Simone et al. Dilemas e desafios da Pós-Graduação em Educação Física. ljuí: Editora Unijuí, 2015. p.15-56.

TAFFAREL, Celi; ESCOBAR, Micheli Ortega. Mas, afinal, o que é Educação Física?: um exemplo do simplismo intelectual. Movimento, v. 1, n. 1, p. 5-8, 1994.

TRIVIÑOS, Augusto Nibaldo. Introdução à Pesquisa em Ciências Sociais: a Pesquisa Qualitativa em Educação. São Paulo: Atlas, 1987.

Apoio:

presente trabalho foi realizado com apoio da Coordenação de Aperfeiçoamento de Pessoal de Nível Superior -Brasil (CAPES) - Código de Financiamento 001. This study was financed in part by the Coordenação de Aperfeiçoamento de Pessoal de Nível Superior - Brasil (CAPES) - Finance Code 001. 